\title{
SNOW PRESSURE ON RIGID OBSTACLES
}

\author{
By David MaClung* \\ (Geophysics Program, University of Washington, Seattle, Washington 98195, U.S.A.)
}

\begin{abstract}
In this paper a continuum mechanical formulation of snow pressure is given. The snow pressure against retaining structures on slopes is considered in two separate parts: ( 1 ) the static component due to the regression of transverse expansion as discussed by Haefeli, and (2) the dynamic component due to the interruption of the creep (internal deformation) and glide (slip of the entire snow cover over the ground). Snow-pressure calculations made using the non-linear viscous constitutive equations given by McClung (in press) are given for the plane strain-rate problem of a rigid barrier on a snow-covered slope. These calculations are compared with the previous formulation of snow pressure given by Haefeli for the expected range of boundary conditions for the structure and for the snow-earth interface. The results show that the original formulation by Haefeli gives a dynamic component of similar magnitude to the present calculations. Substantial differences are apparent when the up-slope distances for interruption of the creep and glide processes are compared.
\end{abstract}

RÉsumé. Poussée de la neige sur des obstacles rigides. Une formulation mécanique continue de la pression due à la neige est présentée dans cet article. La poussée due à la neige sur des structures de soutènement positionnées sur des pentes est considérée on deux parties séparées: (1) la composante statique due à la régression de l'expansion transversale comme Haefeli l'a discutée et (2) la composante dynamique due à l'interruption du fluage (déformation interne) et du glissement au sol (glissement de l'ensemble de la couverture neigeuse sur le sol). Des calculs de poussée de neige sont effectués en utilisant les équations constitutives non-linéaires et visqueuses proposées par McClung (sous presse), pour le problème de déformation plane d'une barrière rigide sur une pente couverte de neige. Les calculs sont comparés avec la formulation antérieure pour la poussée des neiges de Haefeli, dans les cas de conditions limites que l'ón peut supposer sur la structure et sur la surface de contact neige-sol. Les résultats montrent que la formulation originale de Haefeli prédit pour la composante dynamique un ordre de grandeur semblable a celui des présents résultats. Des différences substantielles sont apparentes quand on compare les distances en amont sur lesquelles sont interruptées le fluage et le glissement.

Zusammenfassung. Schneedruck an starren Hindernissen. Es wird eine kontinuierliche mechanische Formulierung zur Berechnung des Schneedruckes präsentiert. Der Schneedruck gegen Verbauungen an Hängen wird in zwei gesonderten Teilen errechnet: (I) ein statischer Anteil, der durch die Behunderung der Querdehnung erzeugt wird, wie dies Haefeli diskutiert, und (2) ein dynamischer Anteil, der durch Abbruch des Kriechens (interne Verformung) und das Anhalten des Gleitens (Abrutschen der ganzen Schneedecke über den Hang) erzeugt wird. Mittels rheologischer, nicht linearer Grundgleichungen von McClung (im Druck) wird der Schneedruck gegen eine starre Sperre an einem schneebedeckten Hang für den Fall ebenen Dehnungszustandes errechnet. In dem Bereich von Randbedingungen, die infolge der Sperre und Geländeoberfläche zu erwarten sind, werden die Berechnungen mit denen nach den früheren Formeln für Schneedruck von Haefeli verglichen. Es stellt sich heraus, dass die ursprüngliche Formulierung von Haefeli dynamische Druckkomponenten von ähnlicher Grössenordnung wie die vorliegende Formulierung ergeben. Wesentliche Unterschiede erscheinen, wenn man die ermittelten Stauchungsstrecken oberhalb der Sperre vergleicht.

\section{Nomenclature}

$D$ stagnation depth

$g$ acceleration due to gravity

$h$ snow depth measured vertically

$p$ dynamic component of pressure

$u$ component of creep velocity parallel to the slope

$u_{A}$ component of creep velocity parallel to the slope, at the top of the snow-pack

$u_{0}$ glide velocity at the ground

$v$ component of velocity perpendicular to the slope

$x$ coordinate axis parallel to the slope

$x^{\prime}$ back-pressure zone length

$z$ coordinate axis perpendicular to the slope

$\alpha$ slope angle

* Present address: Norges Geotekniske Institutt, Oslo 8, Norway. 

$\beta$ creep angle
$\eta$ effective bulk viscosity
$\mu$ effective shear viscosity
$\rho$ snow density
$\sigma_{x}$ longitudinal stress
$\Sigma_{\mathrm{I}}$ first invariant of the stress tensor
$\langle\tau\rangle$ average shear stress at the base of the snow-pack
$\tau_{x z} \quad$ shear stress

\section{INTRODUCTION}

A calculation of the snow pressure exerted against rigid obstacles on snow-covered slopes may be thought of as having two components. The first part is the calculation of a static component due to the regression of tranverse expansion as suggested by Haefeli (Bader and others, 1939). The second component is the calculation of a dynamic part of the pressure due to the interruption of the viscous processes of creep (internal deformation) and glide (slip of the entire snow cover over the ground). In order to calculate the dynamic component of pressure from a continuum model, two constitutive equations must be known:

(I) the relationship between stress and viscous strain-rate for creep within the snow cover,

(2) the relationship between the shear stress at the bottom of the snow pack and the glide velocity.

Such relationships have been discussed by McClung (in press, unpublished) as a result of measurements of both creep and glide in the neutral zone.

The boundary condition for the retaining structure may be regarded as lying somewhere between the condition for a perfectly rough surface (no slip) and that for a perfectly smooth structure (no shear stress parallel to the structure). McClung (in press) has pointed out that for the creep mechanism of glide, the fundamental measurement, in the neutral zone, is a parameter known as the stagnation depth. When the stagnation depth is known it is possible to formulate the boundary condition at the snow-earth interface. Estimates of the range of stagnation depths expected from field measurements provide the range of boundary conditions to be expected at the snow-earth interface.

The equations given by Haefeli (Bader and others, 1939) can be re-stated in terms of the two fundamental measurements in the neutral zone: the creep angle $\beta$ and the stagnation depth $D$. When this has been done, a direct comparison between the dynamic component of pressure as calculated from the equations of Haefeli and that calculated from the present formulation is possible.

\section{Creep of Well-settled isothermal snow}

Neutral-zone measurements on well-settled isothermal snow which is assumed to obey a viscous flow law show that both the shear and vertical strain-rates are independent of depth (Bader and others, r 939; McClung, in press, unpublished). McClung has pointed out that the simplest constitutive law for isotropic creep which is consistent with these observations is a two-parameter law with the effective shear viscosity $\mu$ and bulk viscosity $\eta$ proportional to $\Sigma_{\mathrm{I}}$, the first invariant of the stress tensor (the bulk stress). Such a formalism provides relationships which are invariant with respect to proper orthogonal coordinate transformations as required by continuum mechanics. The precise relationship between the stress and the viscous strain-rate has not been formulated as yet. Several relationships have been proposed, for example by Brown and others (1973), McClung (in press, unpublished) and Salm (in press). However, neutral-zone measurements of creep strongly indicate that, when a two-parameter 
constitutive law is considered, it is likely that the effective shear and bulk viscosities may be considered to be proportional to the bulk stress. Accordingly, the calculations presented below are based on that assumption. The ratio $\mu / \eta$ is assumed to be constant in the calculations since the precise form of the constitutive law is unknown. Such an assumption is not expected to cause a large error in the magnitude of the calculated pressures.

Formulation OF THE GLIDE-BOUNDARY CONDITION IN THE ZONE OF INFLUENCE OF A STRUCTURE ON A SLOPE

It is unlikely that the distribution of glide velocity or shear stress at the snow-earth interface will ever be known sufficiently well for a formulation to be made of a velocity or stress boundary condition in the zone of influence of a structure on a slope. The proper boundary condition is a relationship between the glide velocity and the shear stress at the base of the snow pack. The distribution of glide velocity and shear stress are then to be calculated from a constitutive equation for glide.

McClung (in press) has suggested a relationship of the form

$$
\langle\tau\rangle=\frac{\mu u_{0}}{D}
$$

for the glide constitutive equation in the case where the glide mechanism is that of creep over rough obstacles at the base of the snow-pack. $\langle\tau\rangle$ is the average basal shear-stress, $\mu$ is the shear viscosity, $u_{0}$ is the glide velocity, and $D$ is the stagnation depth defined as in Figure I (Nye, 1969). For the case where the snow is modeled as a linear, incompressible Newtonian fluid,

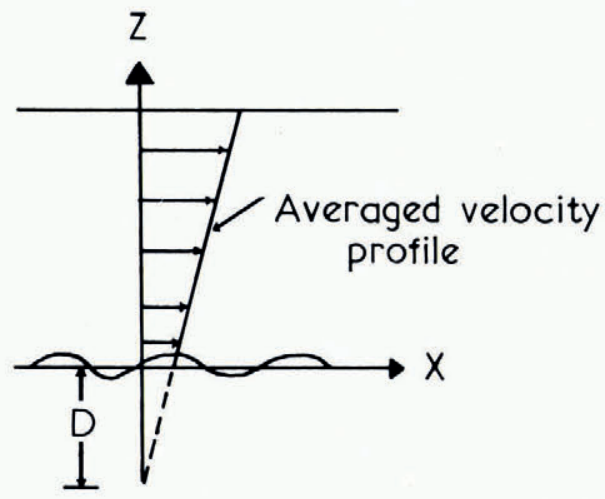

Fig. I. A definition of stagnation depth following $\mathcal{N} y e$ (I969).

$\mu$ is a constant. In that case, Equation (I) is a continuum mechanical formulation of the assumptions made by Haefeli in his formulation of snow pressure. McClung (in press) has also given an approximate equation in an attempt to account for the observed non-linearity in the constitutive law for creep

$$
\langle\tau\rangle=\frac{k \Sigma_{1} u_{0}}{D}
$$

where $k$ is a constant and $\Sigma_{I}$ is the first invariant of the stress tensor. The stagnation depth depends upon the bed topography and the degree of wetness of the interface; this has been discussed in detail by McClung (in press). 


\section{Calculations of SNOW PREssure}

Figure 2 shows the geometry used in the two-dimensional calculations of snow pressure on a rigid retaining structure on a slope. The calculations of dynamic component described here are made using the finite-element method. We assume a situation where a plane strainrate exists and we also assume that the calculation is made over a time interval short enough that overall geometry changes may be ignored. The snow-pack is assumed to be isothermal and have a uniform density. This is typical of the conditions which obtain during the late winter or early spring in the Cascade Mountains, U.S.A. when maximum snow pressures usually occur. Figure 3 shows the finite-element mesh (Zienkiewicz and Cheung, 1967). The calculations presented here assume non-linearity in both the creep and glide constitutive equations because we treat the effective shear and bulk viscosities as being proportional to the bulk stress. The ratio of the shear and bulk viscosity is assumed to be constant and has been defined by some field measurements made by McClung (in press, unpublished).

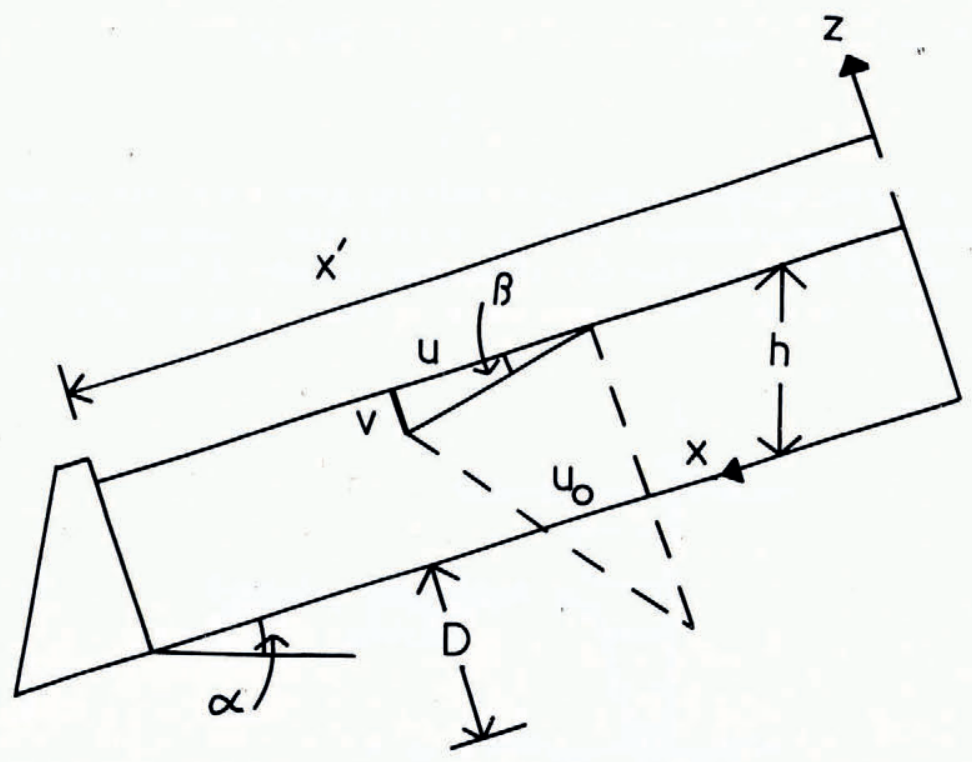

Fig. 2. A diagram which shows the nomenclature used in this paper. $D$ is the stagnation depth; $h$, the snow depth; $u$, the creep velocity parallel to the slope; $u_{0}$, the glide velocity; $v$, the creep velocity perpendicular to the slope; $x^{\prime}$, the back-pressure zone length; $\alpha$, the slope angle; and $\beta$, the creep angle.

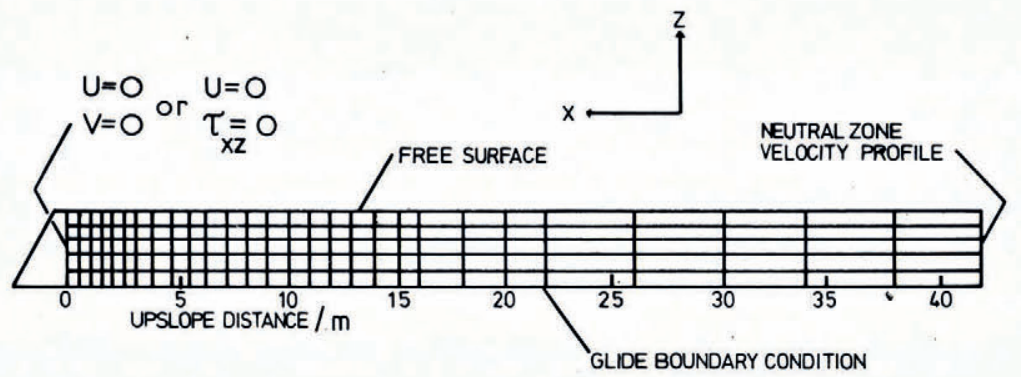

Fig. 3. The finite-element grid. 
SNOW DEPTH / $\mathrm{m}$

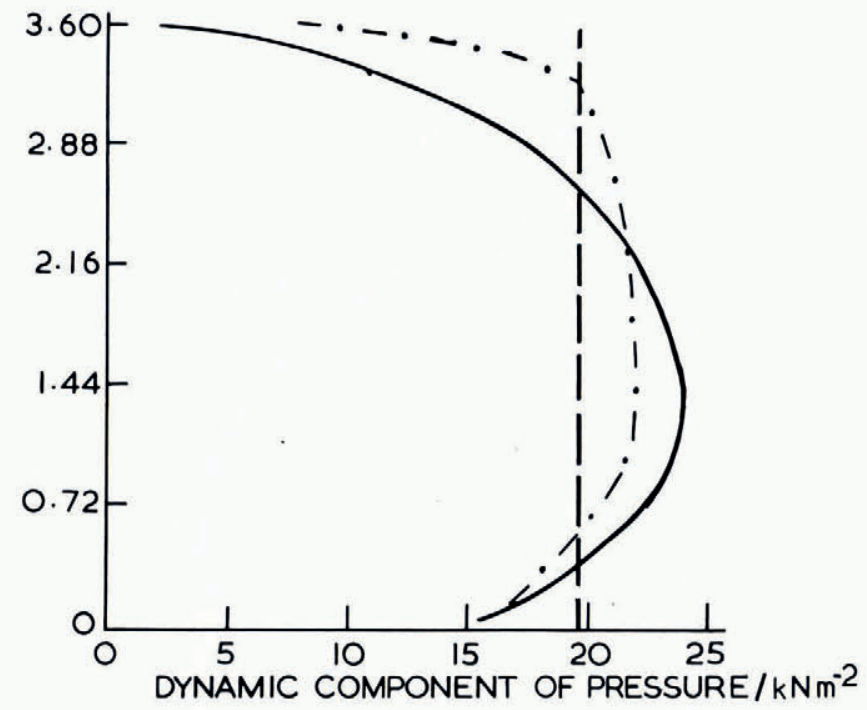

Fig. 4. Snow depth plotted against the dynamic component of pressure. The solid line gives the results of a numerical calculation (the back-pressure zone length is $28 \mathrm{~m}$ ). The broken line gives the result of calculations involving the equations of Haefeli (back-pressure zone length equals $15.5 \mathrm{~m}$ ). The dot-dash line indicates the calculation for constant viscosity. For all calculations $\alpha=45^{\circ}, \beta=16^{\circ}$, and the stagnation depth $=1.13 \mathrm{~m}$. The boundary condition on the structure is: $u=v=o$.

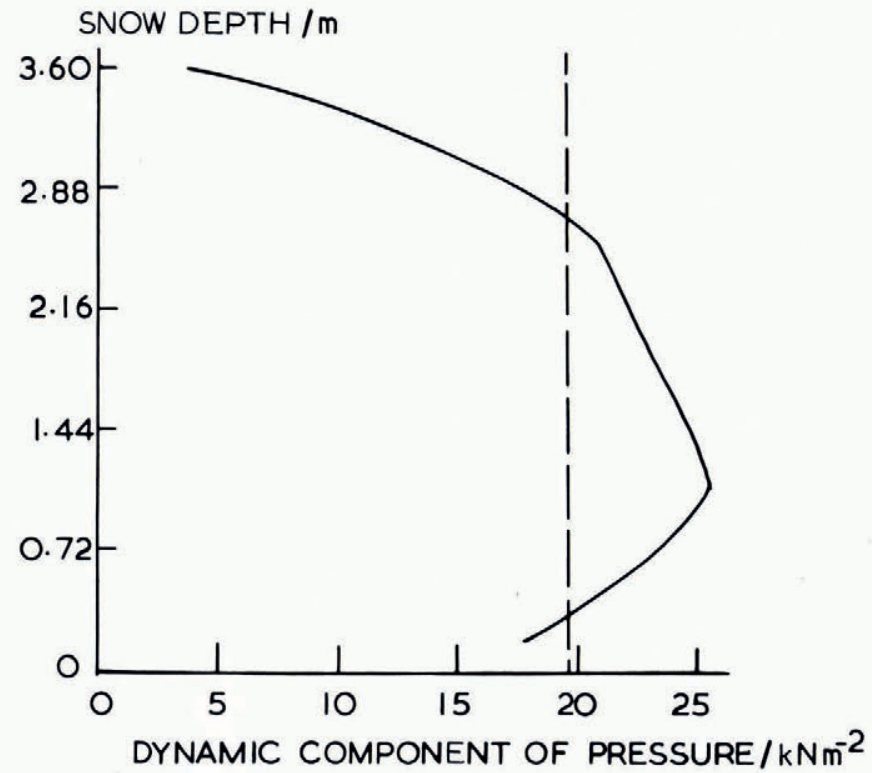

Fig. 5. Snow depth plotted against the dynamic component of pressure. The solid line gives the results of the numerical calculation. The broken line gives the result of calculations involving the equations of Haefeli. The parameters used in the calculations are the same as those used in Figure 4 except for the boundary condition on the structure which is: $u=\tau_{x z}=o$. 
Figures 4-7 show the results of some calculations of the dynamic component of pressurc for conditions which might be expected to occur during the early spring in the Cascade Mountains, U.S.A. Snow density is taken as $55^{\circ} \mathrm{kg} \mathrm{m}^{-3}$, the slope angle is assumed to be $45^{\circ}$ and the effective viscous analog of Poisson's ratio is taken to be 0.3 (this corresponds to a creep angle $\beta$ of ${ }_{1} 6^{\circ}$ ).

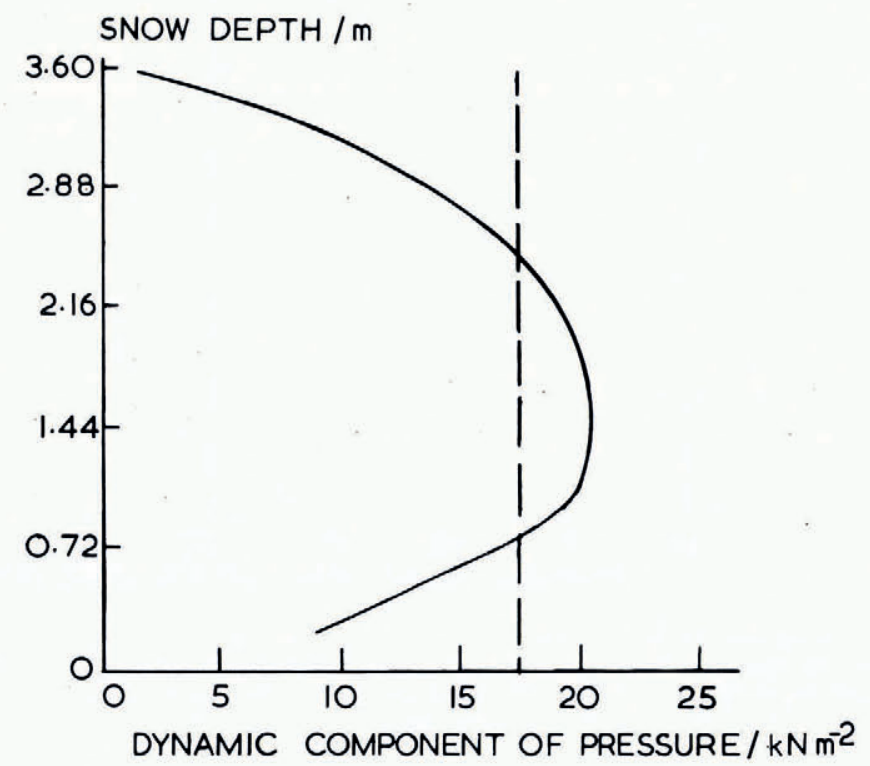

Fig. 6. Snow depth plotted against the dynamic component of pressure. The solid line gives the results of the numerical calculation (the back-pressure zone length is $21 \mathrm{~m}$ ). The broken line gives the results of calculations involving the equations of Haefeli (back-pressure zone length equals $14 \mathrm{~m}$ ). For both calculations $\alpha=45^{\circ}, \beta=16^{\circ}$, and the stagnation depth $=0.215 \mathrm{~m}$. The boundary condition on the structure is: $u=v=0$,

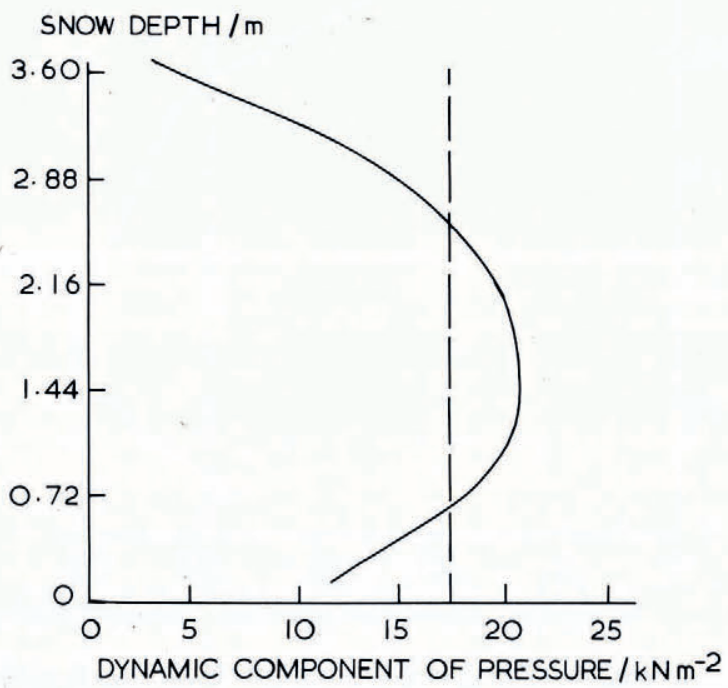

Fig. 7. Snow depth plotted against the dynamic component of pressure. The solid-line gives the results of the numerical calculation. The broken line gives the results of calculations involving the equations of Haefeli. The parameters used in the calculations are the same as those used in Figure 6 except for the boundary condition on the structure which is: $u=\tau_{x z}=o$. 
These calculations were made with a computer program called PLANE 2 whose algorithms assume a condition of plane strain. The program allows the values of viscosity to be different for each element. In addition the program has the ability to incorporate the boundary condition of non-linear slip by allowing input of the ratio of load to glide velocity on the boundary nodes of the snow-earth interface. The calculations were made by an iteration procedure which calculated the shear and bulk velocities during each step and used the calculated values in each successive iteration until convergence was obtained. This convergence condition was usually obtained within three or four iterations for each calculation.

The calculations are given for two different boundary conditions for glide which correspond to stagnation depths of $D=1.13 \mathrm{~m}$ (Figs 4 and 5) and $D=0.215 \mathrm{~m}$ (Figs 6 and 7). The first of these might correspond to a glide condition in which rain and melt water wets the interface whereas the second might correspond to a normal steady-glide condition on a slope of moderate roughness (McClung, in press, unpublished). For both boundary conditions for glide, the calculations were made for two boundary conditions at the structure. If a structure has a perfectly rough surface, this condition is

$$
u=v=0
$$

(corresponding to no slip). For a perfectly smooth structure the condition is

$$
v=\tau_{x z}=\mathrm{o}
$$

(corresponding to no friction on the structure). The boundary condition at the snow-air interface is assumed to be a free surface. The boundary condition up-slope of the barrier is assumed to be the neutral-zone distribution of creep velocity.

The static component of pressure may be taken as the neutral-zone longitudinal stress perpendicular to the barrier $\sigma_{x}$. Under the assumption of a constant ratio of shear to bulk viscosity the relationship is:

$$
\begin{aligned}
\sigma_{x} & =-\left(\frac{3 \eta-2 \mu}{3 \eta+4 \mu}\right) \rho g z \cos \alpha \\
& =-K_{0} \rho g z \cos \alpha
\end{aligned}
$$

where $K_{0}=0.43$ and is defined by the field measurements of McClung (in press, unpublished). In this case, the static component of pressure varies linearly with depth from zero at the snowair interface to $5.9 \mathrm{kN} \mathrm{m}^{-2}$ at the snow-earth interface. These values must be added to the calculated dynamic components of pressure in each case to yield the total snow pressure.

\section{Comparison With the equations of Haefeli}

It is instructive to compare the results presented here with those given by Haefeli (Bader and others, 1939). Haefeli's equations may be re-stated in terms of the two fundamental neutral-zone measurements given by continuum mechanics: the creep angle $\beta$ (Perla, unpublished) and the stagnation depth $D$.

Haefeli gives the following relationship for the up-slope zone of influence (back-pressure zone):

$$
x^{\prime}=h\left[2 \cot \beta\left(\mathrm{I}+2 \frac{u_{0}}{u_{A}}\right) \cot \alpha\right]^{\frac{1}{2}}
$$

where $u_{0}$ is the creep velocity at the ground, $u_{A}$ is the creep velocity at the top of the snow pack and $h$ is the snow depth. The equation may be restated in terms of the geometry given in Figure $I$ as

$$
x^{\prime}=h\left[2 \cot \beta\left(\mathrm{I}+\frac{2 D}{D+h}\right) \cot \alpha\right]^{\frac{1}{2}} .
$$

Haefeli gives the dynamic component of pressure as

$$
p=\frac{1}{3} x^{\prime} \rho g \sin \alpha
$$


where $\rho$ is the snow density. Figures $4-7$ show comparisons of Haefeli's estimates of the dynamic component of pressure and back-pressure zone lengths with the present results. Figure 4 also shows a comparison with the case where the linear creep and glide constitutive equations are used.

The results of such calculations indicate that the estimates of the dynamic component of pressure made by Haefeli are in reasonable agreement with the formulation presented here. Thus, Haefeli's estimates are very useful when an estimate of the snow pressure is needed quickly. On the other hand, when we need to know the distribution of pressure on the structure, or when complicated geometries are involved, the numerical method may be needed.

The estimates of back-pressure zone lengths given by the equations of Haefeli do not agree very closely with the present formulation. The apparent reason is that Haefeli arbitrarily assumed a parabolic distribution of glide velocity and shear stress in the back-pressure zone. The glide velocity and shear stress calculated by the finite element method lead to a function which approaches the estimates of the neutral zone more slowly and thus produces longer back-pressure zones.

Figure 8 shows the calculated distribution of glide velocity in the back-pressure zone for the creep and glide constitutive equations in both the linear and non-linear cases when the stagnation depth $D$ is taken as $1.13 \mathrm{~m}$. There is no difference between the linear and nonlinear formulation for the zone of influence for glide in this case, because the constant viscosities chosen for the linear calculation were for the estimates at the bottom of the snow-pack in the neutral zone.

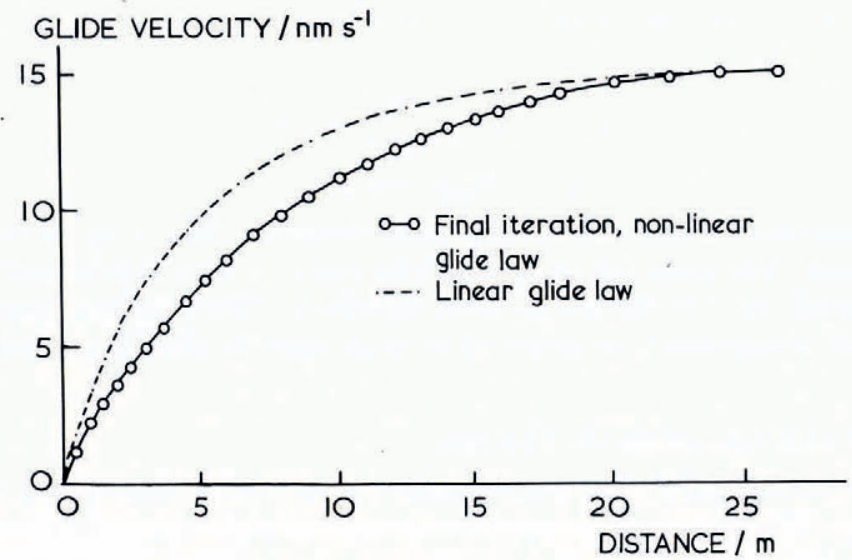

Fig. 8. The distribution of glide velocity in the back-pressure zone length for a stagnation depth of $1.13 \mathrm{~m}$ and a boundary condition on the structure of $u=v=o$.

\section{SUMMARY}

A method has been given for the calculation of snow pressure. This method stems from a continuum-mechanical formulation of the problem. The static component of pressure is equivalent to that given by Haefeli (Bader and others, 1939). The dynamic component of pressure is calculated by the finite element method with the assumption of non-linear viscous creep and glide constitutive equations. The technique proposed here is potentially very powerful. Any slope geometry, barrier geometry, distribution of density and distribution of ground roughness are easily incorporated into the calculations. The method gives, in addition, the distribution of pressure on the structure. 
The numerical calculations presented here show a reasonable agreement with the estimates of Haefeli for the magnitude of the dynamic component of pressure. There is, however, some disagreement in the prediction of the length of the back-pressure zone. The calculations indicate that the pressure is not very sensitive to the boundary condition on the structure, and that the dynamic component of pressure is sensitive to the snow-earth boundary condition. This agrees with field observations which suggest that fast glide is an important determining factor for snow pressure. With regard to the calculations in which the larger stagnation depth was used, it was assumed that increased amounts of water from melting or rainfall affects glide by increasing the stagnation depth. Clearly, the properties of the snow will also be affected by the presence of water. It is then better to regard the calculations as a study into the sensitivity with which the chosen model for the glide boundary condition affects the dynamic component of pressure.

Non-linearity in the constitutive equations has the effect of increasing the snow viscosity in the vicinity of the structure. Increase in the viscosity causes a decrease in the glide velocity near the structure as shown in Figure 8. The model chosen here shows that the non-linearity in creep tends to increase the pressure and shift the force resultant toward the bottom of the structure. Since the exact form of the constitutive equation for viscous creep is, at present, unknown, these results are derived from the assumption of a constant ratio of shear to bulk viscosity.

\section{Acknowledgements}

This study was made as part of my doctoral research in geophysics at the University of Washington. I am indebted to Professors C. B. Brown and R. J. Evans for their useful discussions with me regarding this work and to Professor E. R. LaChapelle for his provision of financial support and encouragement. This research was funded by the Washington State Highway Department under Contract Y-ı 3or. Norges Geotekniske Institutt provided support during the preparation of the manuscript.

MS. received 23 June 1975 and in revised form 20 September 1975

\section{REFERENGES}

Bader, H., and others. I939. Der Schnee und seine Metamorphose, von H. Bader, R. Haefeli, E. Bucher, J. Neher, O. Eckel, C. Thams, P. Niggli. Beiträge zur Geologie der Schweiz. Geotechnische Serie. Hydrologie, Lief. 3. [English translation: U.S. Snow, Ice and Permafrost Research Establishment. Translation 14, 1954.]

Brown, C. B., and others. 1973. Incorporation of glide and creep measurements into snow slab mechanics, by C. B. Brown, R. J. Evans and D. McClung. U.S. Dept. of Agriculture. Forest Service. General Technical Report RM-3, p. 7-13.

McClung, D. M. In press. Creep and the snow-earth interface condition in the seasonal Alpine snow-pack. [Union Géodésique et Géophysique Internationale. Association Internationale d'Hydrologie Scientifique. Commission de Neiges et Glaces. International Symposium on Snow Mechanics, Grindelwald, Switzerland, I-5 April r 974.]

McClung, D. M. Unpublished. Avalanche defense mechanics. [Ph.D. thesis, University of Washington, Seattle, Washington, 1974.]

Nye, J. F. 1969. A calculation of the sliding of ice over a wavy surface using a Newtonian viscous approximation. Proceedings of the Royal Society of London, Ser. A, Vol. 311 , No. 1506 , p. 445-67.

Perla, R. I. Unpublished. The slab avalanche. [Ph.D. thesis, University of Utah, Salt Lake City, Utah, 1971.]

Salm, B. In press. A constitutive equation for creeping snow. [Union Géodésique et Géophysique Internationale. Association Internationale d'Hydrologie Scientifique. Commission de Neiges et Glaces. International Symposium on Snow Mechanics, Grindelwald, Switzerland, I-5 April r 974.]

Zienkiewicz, O. C., and Cheung, Y. K. 1967 . The finite element method in structural and continuum mechanics. London, McGraw-Hill Publishing Co. Ltd. 